\title{
A episiotomia na visão da obstetrícia humanizada: reflexões a partir dos estudos sociais da ciência e tecnologia
}

\author{
Episiotomy from the perspective of humanized obstetrics: \\ reflections based on social studies of science and technology
}

\author{
Cristiane Kämpf \\ Mestranda, Faculdade de Ciências \\ Aplicadas/Universidade Estadual \\ de Campinas. \\ Limeira - SP - Brasil \\ cristiane.kampf@fca.unicamp.br
}

\section{Rafael de Brito Dias}

Professor, Faculdade de Ciências Aplicadas/Universidade Estadual de Campinas.

Limeira - SP - Brasil

rafael.dias@fca.unicamp.br

Recebido em 10 out. 2017.

Aprovado em 6 mar. 2018.
KÄMPF, Cristiane; DIAS, Rafael de Brito. A episiotomia na visão da obstetrícia humanizada: reflexões a partir dos estudos sociais da ciência e tecnologia. História, Ciências, Saúde - Manguinhos, Rio de Janeiro, v.25, n.4, out.-dez. 2018, p.1155-1160.

Resumo

O texto pretende construir uma análise inicial sobre a forma como obstetras ativistas da humanização do parto e do nascimento no Brasil entendem e analisam a prática da episiotomia, intervenção técnica convencional nos protocolos obstétricos que aprenderam durante suas formações médicas e a qual posteriormente abandonaram. Apresentamos uma construção analítica inicial pela ótica dos estudos sociais da ciência e tecnologia e levantamos questionamentos sobre os conceitos de neutralidade da ciência e das tecnologias e imparcialidade do profissional especialista/cientista. Buscamos, ainda, apontar as relações que parecem se estabelecer entre atuação política, produção de conhecimento científico e atuação técnica na prática profissional dos referidos obstetras.

Palavras-chave: episiotomia; obstetrícia; humanização do parto; ciência; tecnologia.

\begin{abstract}
An initial analysis is made of the way obstetricians that defend the humanization of childbirth in Brazil understand and analyze the practice of episiotomy, a conventional technique included in protocols in obstetrics that they had learned in medical training and subsequently abandoned. We present an initial analytical construct through the prism of the social studies of science and technology and raise questions about the neutrality of science and technology and the impartiality of the specialist/scientist. We further point out the relationships that seem to exist between political activity, the production of scientific knowledge, and technical activities in the professional work of the aforementioned obstetricians.
\end{abstract}

Keywords: episiotomy; obstetrics; humanization of childbirth; science; technology.

http://dx.doi.org/10.1590/S0104-59702018000500013 
$\mathrm{N}^{\mathrm{a}}$ presente nota de pesquisa, buscamos construir uma análise inicial sobre a forma como obstetras ativistas do movimento pela humanização do parto e do nascimento no Brasil entendem e analisam a prática da episiotomia - corte cirúrgico na pele e músculos realizado na região entre a vagina e o ânus da mulher (períneo), normalmente com a justificativa controversa de proteger os órgãos genitais femininos de lacerações graves e facilitar a passagem do feto pelo canal de parto, promovendo seu desprendimento mais rápido do corpo da mãe.

Em vários países, recomenda-se o uso dessa técnica em somente cerca de $10 \%$ a $15 \%$ dos casos, nos quais o períneo não consegue dilatação suficiente - muitas vezes por causa de uma episiotomia em um parto anterior (Diniz, Duarte, 2004). No Brasil, a episiotomia é a única cirurgia realizada no corpo de uma mulher saudável sem que seja necessário seu consentimento prévio. Trata-se de um procedimento atualmente praticado em 53,5\% das parturientes brasileiras que fazem parto normal (Leal et al., 2014), número muito acima do limite de 15\% recomendado pela Organização Mundial da Saúde (OMS).

Parece ser preponderante no imaginário médico brasileiro a associação entre intervenções como as cesarianas e valores como higiene, limpeza e controle, numa espécie de normatização do parto fortemente influenciada pelo obstetra Jorge de Rezende, como nos lembram Nakano, Bonan e Teixeira (2016). Os autores oferecem uma valiosa contribuição para pensar os conhecimentos e práticas mais aceitos por uma determinada comunidade como resultado da capacidade de determinados autores mobilizar redes e recursos.

No âmbito da pesquisa hoje em curso, entrevistamos sete obstetras (homens e mulheres) sobre questões diversas relativas às suas experiências profissionais e entendimentos pessoais em obstetrícia, atuações no movimento e formas de construção de conhecimento científico e prático a respeito do processo de parto e nascimento. Para a pesquisa, selecionamos aspectos relacionados ao processo de aprendizado e posterior rejeição à realização da técnica da episiotomia e procuramos entendê-los ou analisá-los a partir de certas reflexões teóricas de autores do campo dos estudos sociais da ciência e tecnologia e da sociologia e antropologia da ciência (Sismondo, 2004). Apresentamos aqui alguns apontamentos gerais, derivados dos resultados parciais da investigação em curso.

Especificamente sobre a análise de práticas médicas como "práticas sociais, sujeitas ao arbítrio humano e construídas dentro de amplas redes de negociações e conflitos os mais diversos" (Collins, Pinch, 2005, p.XI), apoiam-nos, entre outros, os sociólogos da ciência e da tecnologia Harry Collins e Trevor Pinch, que entendem a ciência e a técnica como produtos da realização humana - assim como outras formas de conhecimento, as quais fazem sentido em contextos sociais específicos - e os fatos científicos como construções sociais, "nem mais e nem menos racionais que outros fatos sociais" (p.XI). Para esses autores, pensar sobre ciência, tecnologia e práticas médicas é pensar sobre política:

a saúde se tornou uma questão política. Existem as crises contínuas e cada vez piores no âmbito da saúde mundial em torno da Aids, tuberculose, Sars, ou apenas simplesmente da pobreza. Existe o escândalo daqueles sem plano de saúde nos Estados Unidos. Existe a dinâmica esmagadora da medicina e alta tecnologia e alto custo e as indústrias que se beneficiam com isso - as empresas de plano de saúde, as grandes 
indústrias farmacêuticas - face às evidências esmagadoras de que a prevenção funciona melhor do que a cura. ... Existe toda a supermedicalização da vida moderna, com sua densa população de doenças recém-definidas, como o transtorno do déficit de atenção. Todos esses fatores se tornaram parte do cenário político e médico. Com muita frequência, conversar sobre as grandes questões da saúde é conversar sobre política (Collins, Pinch, 2005, p.218).

Tais apontamentos fazem todo sentido quando se verifica a existência de um (relativamente recente) movimento político-científico nacional e internacional que não só questiona e subverte conhecimentos, práticas científicas e protocolos técnicos tradicionais em obstetrícia, mas reivindica a devolução do protagonismo da cena de parto à mulher (papel no momento tomado pela tecnologia e pela figura do médico); o entendimento do parto como evento fisiológico do corpo feminino - e não como patologia e ato médico; e alterações estruturais em políticas públicas relativas ao atual modelo de atenção ao parto e ao nascimento no país.

Diversos especialistas da atenção ao parto (entre eles os obstetras ativistas) sustentam ideias como a de que "é preciso saber muito para não intervir", ou seja, é preciso conhecer profundamente a fisiologia do parto para conseguir resistir à tentação de aplicar as técnicas e os procedimentos intervencionistas aprendidos e treinados durante a formação médica.

Bastante conhecida entre ativistas especialistas e não especialistas da obstetrícia humanizada, a afirmação "o parto mais científico é o menos tecnológico" significa que quanto mais conhecimento científico o obstetra tiver sobre a fisiologia de um parto de risco habitual, menos intervenções técnicas aplicará durante o processo, pois conhece os ritmos de suas diferentes fases (pródomos, fase ativa, fase expulsiva etc.) e a forma como ele normalmente transcorre, sabendo intervir apenas se e quando necessário, conforme orienta a Medicina Baseada em Evidências (MBE) e a OMS. Os obstetras que entrevistamos afirmam que o uso intenso e rotineiro da episiotomia durante a maioria dos partos no Brasil pode significar falta de conhecimento teórico e prático sobre a fisiologia do períneo e do período expulsivo do parto e pode ser considerado como consequência - ainda que não exclusiva - da formação médica, que em geral entende a gravidez como doença e o parto como necessariamente disfuncional e perigoso e, portanto, dependente de intervenções contínuas.

Uma das obstetras entrevistadas, formada em uma das melhores faculdades de medicina do país, afirmou que "durante a graduação se ensinava que parto normal era realmente melhor que cesárea, mas muito perigoso e imprevisível, dependendo, portanto, de intervenções médicas o tempo todo". Atualmente, essa médica é docente de obstetrícia em uma universidade federal, mas, no início de sua carreira, ela atuava em seu consultório e realizava mais cesarianas que partos normais, durante os quais também realizava a episiotomia. Em entrevista, ela conta que somente depois de começar a questionar o que havia aprendido durante sua formação e ter passado a reestudar obstetrícia é que a fisiologia do parto ficou evidente, provocando uma reestruturação completa de suas práticas profissionais:

resolvi estudar de novo assistência ao parto, ajudada por pessoas que já faziam parte do movimento da humanização, e descobri a medicina baseada em evidências depois 
de dez anos de formada. $\mathrm{O}$ aspecto fisiológico do parto ficou patente, e eu passei a ter medo das intervenções, e não da assistência. E comecei a ter objeção de consciência para realização de cesarianas eletivas, o que antes eu não achava tão grave assim. (Kämpf, 10 out. 2013)

É interessante observar o que essa profissional afirma sobre sua mudança de prática em relação à episiotomia. Quando atendia partos vaginais em seu consultório, a médica utilizava a técnica de forma rotineira, em todos os partos, sem questionar sua necessidade, conforme havia aprendido em sua formação. Após entrar em contato com a MBE e o movimento de humanização, que aponta os danos causados e contesta a efetividade ou necessidade de realização do procedimento, a obstetra afirma que continuou "engessada" em sua prática, e sentindo necessidade de realizá-lo. A primeira vez que constatou que de fato não era necessário cortar o períneo da mulher durante o período expulsivo do parto foi quando uma paciente a proibiu de fazê-lo:

Eu lembro que conversei com uma gestante e disse que não cortaria o períneo. Isso faz 10 anos. Foi combinado que eu não faria a episiotomia porque não precisava e, na hora que ela estava no expulsivo, eu ainda estava bastante engessada da minha prática, então eu tinha montado uma mesa com instrumentos para o parto, coisa que eu não faço mais, e a tesoura estava lá em cima da mesa. Na hora que começou a coroar o bebê, na minha percepção, parecia que ele havia começado a se enroscar pra sair e eu pus a mão na tesoura em cima da mesa. Ela enfiou a mão por trás das costas e colocou a mão inteira na parte do períneo e olhou pra mim e falou 'não me corte'. Eu nem senti que larguei a tesoura, só me lembro do barulho dela caindo. Fiquei paralisada. Mas foi muito importante porque esse foi o primeiro períneo que eu não suturei e aí eu vi que realmente não precisava. Eu acho que nesse momento era muito importante que ela soubesse disso mais do que eu. ${ }^{1}$

A médica conta que, mesmo após essa experiência, continuou realizando episiotomias, pois ainda não havia decidido parar. Ela relata outro parto no qual decidiu não realizar o corte, mas ficou "muito agoniada e sem saber o que fazer", teve de "desfocar e buscar outras coisas pra fazer e pensar", e só assim conseguiu não cortar. A partir de então, ela foi diminuindo a realização do procedimento, e atualmente não o realiza mais. Aos seus alunos, ela ensina maneiras, dicas e técnicas para evitar a realização do corte, defendendo que as mulheres têm o direito de ter seu períneo preservado durante o parto.

Especialistas ligados à obstetrícia humanizada apontam artigos científicos que demonstram crescentes evidências de que a episiotomia não deve ser realizada rotineiramente (Amorim, 2014) e dão seus testemunhos pessoais sobre como conseguiram abandonar, ou mesmo nunca adotar, o procedimento durante a vida profissional. Muitos médicos, entretanto, continuam a defender a necessidade de uso, ainda que seletivo, dessa técnica. A discussão sobre o procedimento envolve não somente o embate entre especialistas, mas inclui a participação e sofre influências de diversos outros atores ligados ao tema: movimento feminista em saúde; advogadas e advogados; organizações não governamentais de proteção e defesa dos direitos das mulheres; grupos de gestantes; obstetrizes, enfermeiras obstétricas, doulas, políticos, jornalistas, representantes de 
hospitais, planos de saúde e entidades da classe médica, a Agência Nacional de Saúde e o Ministério Público de São Paulo - o qual inclusive já organizou audiências públicas sobre o tema em 2014 e 2015 (MPF, 17 out. 2014). Esse é, portanto, um exemplo bastante claro de como uma discussão técnica perfaz também uma discussão política, econômica, social e cultural. Laboratórios, hospitais, redes virtuais, meios de comunicação, tribunais, o âmbito privado doméstico e tantos outros espaços, dessa forma, estão de certa maneira conectados e operam, conjuntamente, no sentido de moldar as dinâmicas tecnocientíficas que afetam, inclusive, a forma como se nasce.

À guisa de conclusão, notamos que está em franco processo de mudança a forma de se construir conhecimento prático, técnico e científico sobre o processo de parto e nascimento no Brasil e, mais especificamente, acerca da prática da episiotomia. Obstetras que ao longo de suas carreiras profissionais tornaram-se parte do Movimento pela Humanização do Parto e do Nascimento no Brasil (MHPNB) estabeleceram novos modos de pensar e entender a realização do procedimento. Atualmente, tanto a produção científica quanto a prática técnica e docente desses médicos questionam de forma vigorosa a necessidade de realização do procedimento, chegando mesmo a rechaçá-lo, considerando-o muitas vezes nada mais que mutilação dos órgãos genitais femininos.

O movimento feminista em saúde, desde suas origens na Inglaterra, no início do século $\mathrm{XX}$, com o movimento pelo parto ativo, já questionava a existência de comprovações científicas sólidas que justificassem a necessidade de realização rotineira do procedimento (Balaskas, 2015, p.33). Tais questionamentos são relembrados e reforçados nos dias de hoje por diversos atores do MHPNB, entre eles os próprios obstetras, outros profissionais de saúde que atuam na atenção ao parto e ao nascimento e também pelas próprias mulheres parturientes e suas famílias, não especialistas, mas informadas sobre as controvérsias científicas presentes (não somente) na obstetrícia e cientes de seus direitos como pacientes.

Acima de tudo, e concordando com autoras como Felitti (2011), parece-nos particularmente relevante refletir sobre o debate acerca do parto e dos conhecimentos e técnicas que ele movimenta, com o objetivo de pensar o lugar das parturientes no momento do nascimento de suas filhas e seus filhos, de modo que não continuem sendo coadjuvantes invisíveis de um processo muitas vezes entendido meramente como um ato médico no qual as técnicas e os instrumentos são os protagonistas.

\section{NOTA}

${ }^{1}$ Este é um fragmento de entrevista semiestruturada realizada em 2016 com uma médica obstetra ativista do movimento pela humanização do parto e do nascimento no Brasil. Essa médica é também pesquisadora da ciência obstétrica e docente de um curso de medicina em uma universidade federal do estado de São Paulo. A entrevista foi realizada via Skype, e os assuntos abordados referem-se à história pessoal e profissional da médica, com foco na transição epistemológica ocorrida a partir do momento em que começou a questionar-se sobre práticas tradicionais em obstetrícia, como a episiotomia. Depois de transcrita e analisada, fragmentos da entrevista, como o apresentado nesta nota, estão sendo utilizados em pesquisa de mestrado ainda em andamento. 


\section{REFERÊNCIAS}

AMORIM, Melania.

Cuidado perineal: 12 anos sem episiotomia.

Disponível em: <http://estudamelania.blogspot. com.br/2012/08/estudando-episiotomia-voz-dasmulheres.html>. Acesso em: 10 out. 2017. 2014.

BALASKAS, Janet.

Parto ativo: guia prático para o parto natural (A história e a filosofia de uma revolução). São Paulo: Aquariana; Ground. 2015.

COLLINS, Harry; PINCH, Trevor.

Doutor Golem: como pensar a medicina. Belo Horizonte: Fabrefactum. 2010.

DINIZ, Carmen S.G.; DUARTE, Ana C. Parto normal ou cesárea? O que toda mulher deve saber (e todo homem também). São Paulo: Editora Unesp. 2004.

FELITTI, Karina.

Parirás sin dolor: poder médico, género y política en las nuevas formas de atención del parto en la Argentina (1960-1980). História, Ciências, Saúde-Manguinhos, v.18, supl.1, p.113151. 2011.

KÄMPF, Cristiane.

Modelo obstétrico brasileiro ignora evidências científicas e recomendações da OMS na assistência ao parto. Com Ciência. Disponível em: <www.comciencia.br/comciencia/handler. php? section $=8 \&$ edicao $=92 \& i d=1139>$. Acesso em: 19 out. 2018. 10 out. 2013.

LEAL, Maria do C. et al.

Intervenções obstétricas durante o trabalho de parto e parto em mulheres brasileiras de risco habitual. Cadernos de Saúde Pública, v.30. supl.1, p.17-47. 2014.

MPF.

Ministério Público Federal. MPF em São

Paulo realiza audiência pública para debater episiotomia e humanização do nascimento. Disponível em: <http://pfdc.pgr.mpf.mp.br/ informativos/edicoes-2014/outubro/mpfsp-realiza-audiencia-publica-para-debaterepisiotomia-e-humanizacao-do-nascimento/>. 17 out. 2014.

NAKANO, Andreza R.; BONAN, Claudia; TEIXEIRA, Luiz A.

Cesárea, aperfeiçoando a técnica e normatizando a prática: uma análise do livro Obstetrícia, de Jorge de Rezende. Revista História, Ciências, Saúde - Manguinhos, v.23, n.1, p.155172. 2016.

SISMONDO, Sergio.

An introduction to science and technology studies. Oxford: Blackwell Publishing. 2004.

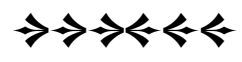

